\title{
Application of REDOR subtraction for filtered MAS observation of labeled backbone carbons of membrane-bound fusion peptides
}

\author{
Jun Yang, Paul D. Parkanzky, Michele L. Bodner, Craig A. Duskin, and David P. Weliky* \\ Department of Chemistry, Michigan State University, East Lansing, MI 48824, USA
}

Received 17 December 2001; revised 5 August 2002

\begin{abstract}
Clean MAS observation of ${ }^{13} \mathrm{C}$-labeled carbons in membrane-bound HIV-1 and influenza fusion peptides was made by using a rotational-echo double-resonance spectroscopy (REDOR) filter of directly bonded ${ }^{13} \mathrm{C}-{ }^{15} \mathrm{~N}$ pairs. The clean filtering achieved with the REDOR approach is superior to filtering done with sample difference spectroscopy. In one labeling approach, the peptide had labels at a single ${ }^{13} \mathrm{C}$ carbonyl and its directly bonded ${ }^{15} \mathrm{~N}$. The resulting chemical shift distribution of the filtered signal is used to assess the distribution of local secondary structures at the labeled carbonyl. For the influenza peptide, the Leu-2 carbonyl chemical shift distribution is shown to vary markedly with lipid and detergent composition, as well as peptide:lipid ratio, suggesting that the local peptide structure also has a strong dependence on these factors. Because most carboxylic- and amino-labeled amino acids are commercially available, this REDOR approach should have broad applicability to chemically synthesized peptides as well as bacterially synthesized proteins. In a second labeling approach, the HIV-1 fusion peptide had $\mathrm{U}-{ }^{13} \mathrm{C},{ }^{15} \mathrm{~N}$ labeling over three sequential residues. When a $1.6 \mathrm{~ms}$ REDOR dephasing time is used, only backbone ${ }^{13} \mathrm{C}$ signals are observed. The resulting spectra are used to determine spectral linewidths and to assess feasibility of assignment of uniformly labeled peptide.
\end{abstract}

(c) 2002 Elsevier Science (USA). All rights reserved.

Keywords: REDOR; Filter; Peptide; Protein; Carbonyl

\section{Introduction}

Rotational-echo double-resonance spectroscopy (REDOR) is one of the most widely used magic angle spinning (MAS) NMR techniques for analysis of molecular structure in the solid state [1-6]. REDOR has found additional application in detection of formation of chemical bonds [7,8] and in resonance assignment of small peptides [9]. The wide use of REDOR is primarily due to the relative simplicity and robustness of its pulse sequence and data analysis. In this paper, we apply REDOR to the filtered MAS observation of backbone carbons in membrane-bound fusion peptides.

In many biopolymeric systems in the solid state, it is important to filter MAS signals from labeled nuclei of interest out of a large background of natural abundance signals. The chemical shifts and/or chemical shift an-

\footnotetext{
${ }^{*}$ Corresponding author. Fax: 1-517-353-1793.

E-mail address: weliky@cem.msu.edu (D.P. Weliky).
}

isotropies of the filtered labeled signals can provide information about local structure and may be additionally combined with dipolar coupling or other structural measurements [10-20]. The most basic filtering is difference spectroscopy between a sample containing specific labeling and a pure natural abundance sample. To work well, the two samples must be made under nearly identical conditions. For ${ }^{13} \mathrm{C}$ nuclei, there may also be background from the probe, which is subtracted most easily if there is approximately the same amount of material in the labeled and unlabeled samples. In general, sample difference filtering is more difficult for broader labeled resonances and when the labeled site signals are small relative to the natural abundance contributions from the sample and probe.

In samples labeled with two nearby homonuclei (e.g., ${ }^{13} \mathrm{C}$ separated by $<5 \AA$ ), double-quantum MAS methods based on the homonuclear dipolar coupling have been developed which can filter out the natural abundance signal $[15,21-24]$. Because only nearby ${ }^{13} \mathrm{C}-{ }^{13} \mathrm{C}$ pairs are observed with these techniques, ${ }^{13} \mathrm{C}$ natural abundance 
nuclei are typically filtered by a factor of up to $\sim 100$ relative to the labels.

In the present study, REDOR filtering is applied to observe the MAS signals from labeled backbone ${ }^{13} \mathrm{C}$ in membrane-bound fusion peptides. These peptides have similar membrane fusion activity as the viral fusion proteins from which they are derived and thus serve as useful model fusion systems [25]. The goal of solid state NMR structural and dynamical studies on the membrane-bound forms of these peptides is to provide insight into the ways in which they induce membrane fusion $[19,26,27]$. For these systems, REDOR filtering is compared to sample difference spectroscopy and has several advantages including: (1) better filtering of natural abundance signals; (2) requiring one rather than two samples; and (3) better compensation for spectrometer and probe drifts. In one labeling approach, a single ${ }^{13} \mathrm{C}-{ }^{15} \mathrm{~N}$ pair is probed with ${ }^{13} \mathrm{C}$ carbonyl labeling of the residue of interest and ${ }^{15} \mathrm{~N}$ amide labeling of the subsequent residue. Because this labeling scheme uses the most widely available and least expensive labeled amino acids, it can usually be straightforwardly implemented. REDOR filtering is also applied to observe backbone carbons of a membrane-bound fusion peptide which is $\mathrm{U}^{13} \mathrm{C},{ }^{15} \mathrm{~N}$-labeled over three sequential residues.

With the labeling described in this paper, other filtering approaches are possible, including SFAM, TEDOR, and ${ }^{15} \mathrm{~N}-{ }^{13} \mathrm{C}$ cross-polarization. In Section 3, the signal-to-noise of the REDOR approach is compared to previous studies using these other approaches.

\section{Results}

Figs. 1a-h display ${ }^{13} \mathrm{C}$ MAS spectra of membranebound fusion peptide samples which contain 0.3$0.5 \mu \mathrm{mol}$ peptide. In $(\mathrm{a}-\mathrm{d}),(\mathrm{e}-\mathrm{g})$, and $(\mathrm{h})$, the peptide: lipid mol ratios are 1:100, 1:80, and 1:40, respectively. In $(\mathrm{a}-\mathrm{g})$, the samples contained the HFP HIV-1 fusion peptide and in (h), the sample contained the IFP-KKK influenza fusion peptide. In (a), the sample contained a single ${ }^{13} \mathrm{C}$ backbone carbonyl label at Phe- 8 , and in (b), the sample contained unlabeled peptide. Fifty $\mathrm{Hz}$ line broadening and baseline correction was applied to each spectrum. The (a) - (b) difference spectrum is represented in (c). In (d), the difference spectrum is presented between the spectrum of a sample containing a single backbone carbonyl label at Val-2 (not shown) and the (b) spectrum. In a difference spectrum, signals are observed for the labeled isotropic carbonyl resonance at 171-172 ppm and for its $M=+2$ to -2 spinning sidebands. In calculating either (c) or (d), the overall amplitude and chemical shift of the (b) spectrum were each adjusted to give the best compromise in the difference spectrum between absorptive phasing of the labeled carbonyl resonances and minimal $10-60 \mathrm{ppm}$ aliphatic signal.

The labeled Phe-8, labeled Val-2, and unlabeled samples all contained the LM-2 lipid mixture, which approximately reflects the lipid headgroup and cholesterol composition of the target T cells of the HIV-1 virus [28]. The labeled Phe- 8 and unlabeled samples used the same batch of LM-2 while the labeled Val-2 sample used a different LM-2 batch. This difference in sample preparation helps to explain the better subtraction obtained for the Phe-8 sample (c) relative to the Val-2 sample (d).

In (e) and (f), REDOR spectra are displayed for a membrane-bound HIV-1 fusion peptide sample with carbonyl ${ }^{13} \mathrm{C}$ Phe- 8 and amide ${ }^{15} \mathrm{~N}$ Leu-9 labels. The (e) and (f) spectra are for data collected without $\left(S_{0}\right)$ and with $\left(S_{1}\right){ }^{15} \mathrm{~N} \pi$ pulses, respectively. Each spectrum is the average of the same number of transients. The $(\mathrm{g})$ spectrum is derived from the difference between the (e) and (f) FID's. Neither FID was scaled or otherwise adjusted in obtaining the difference. A similar, higher signal-to-noise REDOR difference spectrum is displayed in (h) for an influenza fusion peptide sample with carbonyl ${ }^{13} \mathrm{C}$ Leu-2 and amide ${ }^{15} \mathrm{~N}$ Phe-3 labels. In both (g) and (h), the labeled isotropic carbonyl resonance is observed and in (h), the $M=+1$ and -1 carbonyl sidebands are also apparent. The $(\mathrm{e}-\mathrm{h})$ spectra employed a $1 \mathrm{~ms}$ dephasing period which corresponds to $\sim 90 \%$ ideal REDOR attenuation for a $1.32 \AA \mathrm{C}-\mathrm{N}$ distance [29]. The spectra were all processed with $50 \mathrm{~Hz}$ line broadening and with baseline correction. Similar spectra were obtained for 2 and $3 \mathrm{~ms}$ dephasing periods (not shown). In terms of signal-to-noise, the $3 \mathrm{~ms}$ spectrum was comparable to the $1 \mathrm{~ms}$ spectrum and the $2 \mathrm{~ms}$ spectrum was about $10 \%$ better than the $1 \mathrm{~ms}$ spectrum.

The advantages of the REDOR filtering are clearly shown in a comparison of (c) and (d) with (g) and (h). Using sample difference spectroscopy, it is impossible to completely filter out the lipid aliphatic signals. In addition, the subtraction requires significant judgement in setting the amplitude scaling and chemical shifts of the spectra. By contrast, the REDOR subtraction shows complete filtering of all of the natural abundance signals and requires little judgement in spectral processing.

Fig. 2 displays a further application of REDOR filtering to the influenza fusion peptide associated with different detergent or lipid compositions and at different peptide:lipid ratios. In DPC micelles, the $\mathrm{N}$-terminal region of the fusion peptide is helical [30-32] and this is consistent with the downfield $175 \mathrm{ppm}$ chemical shift observed in Fig. 2a [11]. In (b) and (c), the membrane composition is POPC:POPG:cholesterol $(8: 2: 5 \mathrm{~mol} \mathrm{ra}-$ tio) with peptide:lipid mol ratios of 1:120 and 1:60, respectively. This lipid composition is similar to that used by other investigators except for the presence of cholesterol in our samples and its absence in their samples $[31,33]$. In both (b) and (c), there is a peak at $175 \mathrm{ppm}$ 


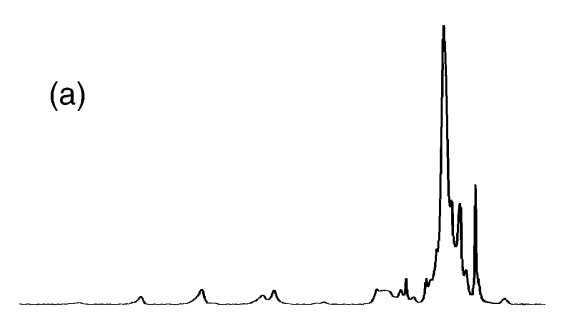

(b)

(c)

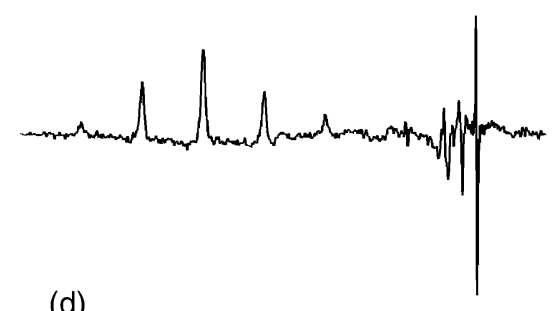

(d)

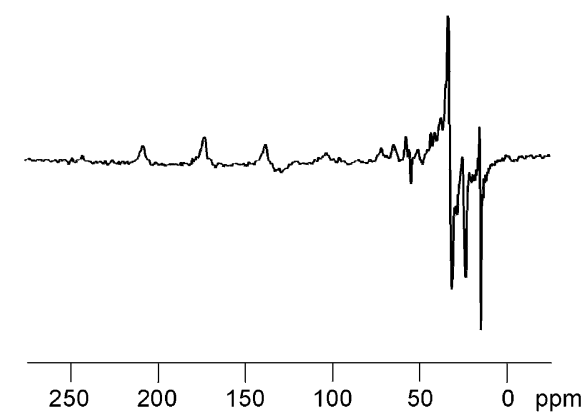

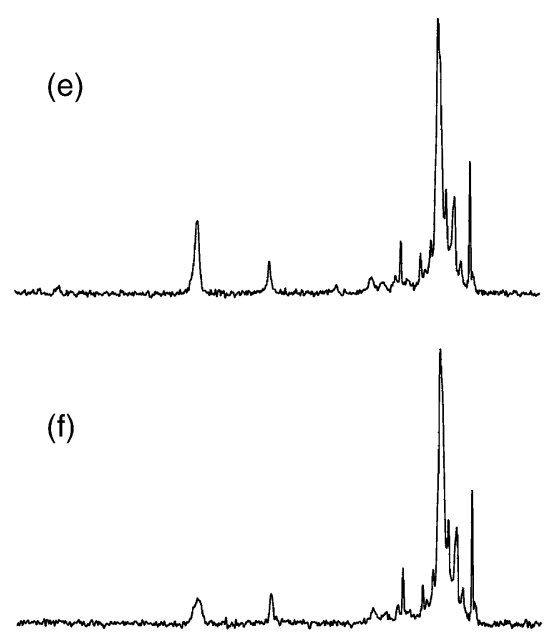

(g)

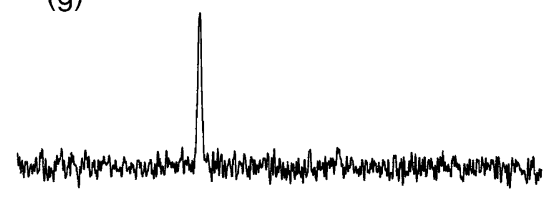

(h)

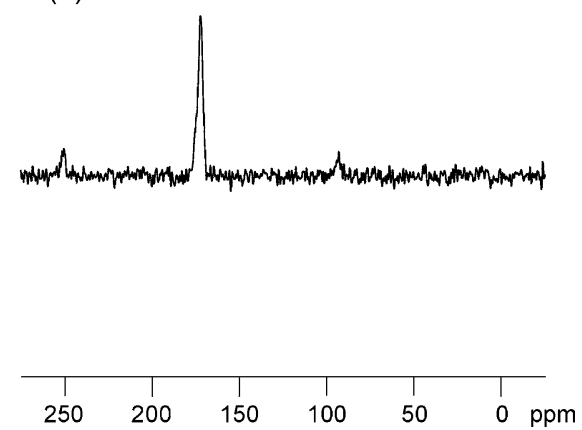

Fig. 1. ${ }^{13} \mathrm{C}$ MAS spectra of membrane-bound fusion peptides. In (a-g), the samples contained the HFP HIV-1 fusion peptide and in (h), the sample contained IFP-KKK influenza fusion peptide. In (a) and (b), cross-polarization spectra are displayed for samples made with Phe- 8 carbonyl-labeled and unlabeled peptide, respectively. The (a) - (b) difference spectrum is presented in (c). In (d), a difference spectrum is displayed between the spectrum of a sample made with Val-2 carbonyl-labeled peptide (not shown) and the (b) spectrum of the unlabeled sample. The spectra in (e) and (f) are the respective $S_{0}$ and $S_{1}$ REDOR spectra obtained from a sample containing peptide which had both a ${ }^{13} \mathrm{C}$ carbonyl label at Phe- 8 and a ${ }^{15} \mathrm{~N}$ amide label at Leu-9. The spectrum in (g) is obtained from processing the $S_{0}-S_{1}$ difference FID. The (h) spectrum was obtained by a method similar to (g) and is for an influenza fusion peptide sample which had both a ${ }^{13} \mathrm{C}$ carbonyl label at Leu-2 and a ${ }^{15} \mathrm{~N}$ label at Phe-3. The MAS frequency is $3.5 \mathrm{kHz}$ for (a-d) and $8.0 \mathrm{kHz}$ for (e-h). The spectra in (a), (b), (e), and (f) represent the averages of 73,660, 117,816, 11,168, and 11,168 scans, respectively. The spectrum of the HIV-1 Val-2-labeled sample (not shown) was the average of 82,576 scans. The $S_{0}$ and $S_{1}$ FID's of the influenza fusion peptide sample (not shown) were each an average of 77,000 scans. $50 \mathrm{~Hz}$ line broadening was applied to the (a), (b), (e-h), and labeled Val-2 spectra.

which by comparison with (a), likely corresponds to a population of peptide with helical structure at Leu-2. In (b) and (c), there is an additional peak at $172 \mathrm{ppm}$, which likely corresponds to a peptide population with non-helical structure at this residue [11]. The 172/ $175 \mathrm{ppm}$ peak intensity ratio is larger at 1:60 peptide:lipid ratio, indicating an increase in the non-helical population at higher peptide:lipid ratios. This trend is confirmed by the spectrum in Fig. 1h which was taken on a sample at 1:40 peptide:lipid ratio and which is dominated by the $172 \mathrm{ppm}$ non-helical peak. Similar changes in the overall peptide structure have been inferred from infrared spectroscopy [34]. Interestingly, we have also seen that the $172 \mathrm{ppm}$ peak is dominant for a sample made with low peptide:lipid ratio and with a lipid composition similar to that of the epithelial 

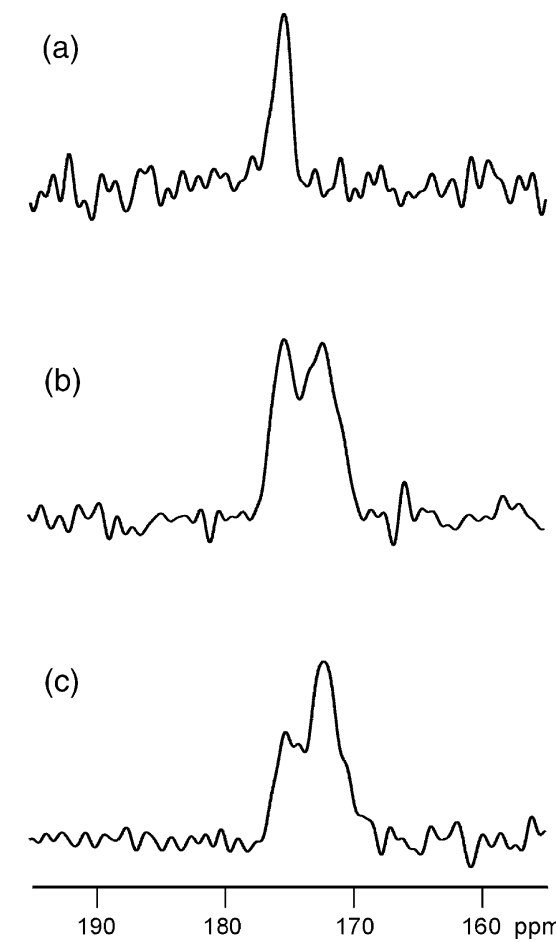

Fig. 2. REDOR difference spectra of the influenza fusion peptide in different detergent and membrane environments. The IFP-GKKKL2CF3N peptide was ${ }^{13} \mathrm{C}$ carbonyl-labeled at Leu-2 and ${ }^{15} \mathrm{~N}$-labeled at Phe-3. In (a), the peptide is in frozen DPC detergent $(200 \mathrm{mM})$ at a peptide:detergent mol ratio of 1:120 while in (b) and (c), the peptide is in POPC:POPG:cholesterol (8:2:5 mol ratio) at peptide:lipid mol ratios of $1: 120$ and $1: 60$, respectively. The sample temperature was $-80^{\circ} \mathrm{C}$ in (a) and $-50{ }^{\circ} \mathrm{C}$ in (b) and (c). Other experimental conditions were: $6 \mathrm{~mm}$ rotor diameter; $160 \mu \mathrm{L}$ sample volume; $8.0 \mathrm{kHz}$ MAS frequency; $1 \mathrm{~ms}$ dephasing time; and $50 \mathrm{~Hz}$ of line broadening. For (a), (b), and (c), the total number of FID's $\left(S_{0}+S_{1}\right)$ were 49530,121344 , and 82688 , respectively.

respiratory cells infected by the influenza virus (data not shown).

Figs. 3a and b display the REDOR $S_{0}$ and difference spectra from the HIV-1 fusion peptide HFP-KKKUF8L9G10 associated with LM-3 at peptide:lipid mol ratio of $\sim 1: 20$. The peptide contains $\mathrm{U}-{ }^{13} \mathrm{C},{ }^{15} \mathrm{~N}$ labeling over the Phe-8, Leu-9, and Gly-10 residues. In the $S_{0}$ spectrum, there is significant natural abundance signal from the lipid and peptide. The difference spectrum was taken with a $1.6 \mathrm{~ms}$ dephasing time and cleanly shows the signals of backbone carbons directly bonded to labeled ${ }^{15} \mathrm{~N}$. The isotropic $\mathrm{C}_{\alpha}$, carbonyl, and $M=+1,-1$, and -2 spinning sidebands of the carbonyls are apparent. Similar spectra were obtained at $1 \mathrm{~ms}$ dephasing time. At longer dephasing times, there are signals from more remote ${ }^{13} \mathrm{C}$ and significant loss of signal and phase twists due to directly bonded ${ }^{13} \mathrm{C}-{ }^{13} \mathrm{C}$ dipolar and $\mathrm{J}$ couplings (data not shown) [35-37]. In (b), the isotropic Phe- 8 and Leu-9 carbonyl signals at 172 ppm are unresolved whereas the 40-55 ppm Phe-8, Leu-9, and Gly-10 $\mathrm{C}_{\alpha}$ signals are all resolved. On the basis of the charac-
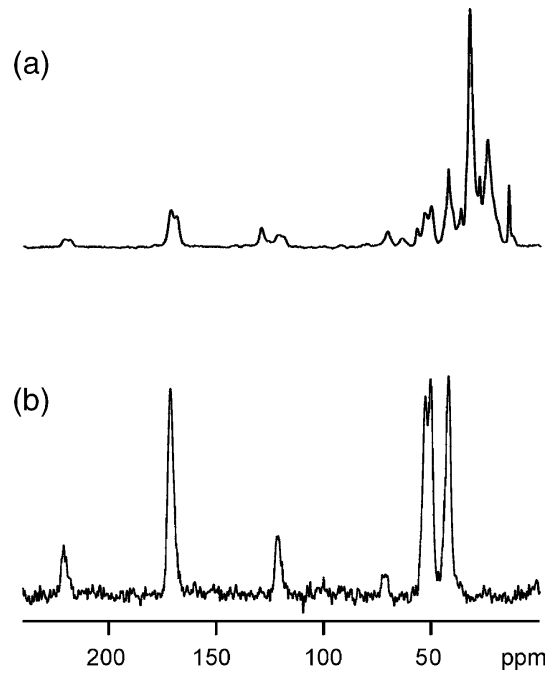

Fig. 3. NMR spectra of LM3-associated HFP-KKK-UF8L9G10. In (a) and (b), $S_{0}$ and REDOR subtraction spectra are respectively displayed. Experimental conditions were: peptide:lipid mol ratio 1:20; $4 \mathrm{~mm}$ rotor diameter; $\sim 60 \mu \mathrm{L}$ sample volume; $5.0 \mathrm{kHz}$ MAS frequency; $1.6 \mathrm{~ms}$ dephasing time; $76.9 \mathrm{ppm}$ transmitter frequency; 21,600 total $\left(S_{0}+S_{1}\right)$ FID's; and $50 \mathrm{~Hz}$ line broadening. The spectral intensity in (b) is multiplied by a factor of eight relative to that in (a). At this dephasing time, only labeled ${ }^{13} \mathrm{C}$ directly bonded to ${ }^{15} \mathrm{~N}$ are observed in the REDOR difference spectrum.

teristic chemical shifts of residue-types, we can tentatively assign the $42.5 \mathrm{ppm}$ signal to the Gly-10 $\mathrm{C}_{\alpha}$ [38]. In this case, the difference spectrum is also useful for assessing linewidths and indirectly, the feasibility of doing a full assignment on this peptide with multidimensional NMR methods. The Gly-10 $\mathrm{C}_{\alpha}$ linewidth is $\sim 2.3 \mathrm{ppm}$ and we expect that a full assignment will be possible for a peptide which is $\mathrm{U}^{13} \mathrm{C},{ }^{15} \mathrm{~N}$-labeled over a significant number of its residues [39].

\section{Discussion}

\subsection{Advantages of REDOR filtering}

In MAS solid state NMR spectra of membranebound peptides and proteins, signals from specifically labeled nuclei can provide important information about the local structure and structural homogeneity $[19,27,40,41]$. However, for ${ }^{13} \mathrm{C}$, these labeled nuclei signals are usually poorly resolved from large natural abundance signals of lipid and protein. In this paper, we investigate two different methods for filtering out these natural abundance signals, sample difference and REDOR difference spectroscopy. The REDOR difference spectroscopy is shown to be a superior filtering method and to be easier to implement because it requires only one rather than two samples. REDOR does require a triple rather than double-resonance spectrometer and 
probe as well as ${ }^{13} \mathrm{C} /{ }^{15} \mathrm{~N}$ labeling rather than just ${ }^{13} \mathrm{C}$ labeling.

The filtering advantages of REDOR are visually demonstrated in comparison of Figs. 1c and d with Figs. $1 \mathrm{~g}$ and $\mathrm{h}$. In our and to some extent others' experience, it is not possible to completely eliminate natural abundance signals in the sample difference spectrum [17,42]. In addition, calculation of the difference spectrum requires significant judgement in adjustment of the scale factors and chemical shifts of the input spectra. The optimal difference spectrum is a compromise and contains significant natural abundance intensity, a rolling baseline, and apparent dispersive phasing of some peaks. For example, in Figs. 1c and d, the upfield side of the $M=-1$ carbonyl sideband appears non-absorptive because of non-ideal subtraction of natural abundance signals around $130 \mathrm{ppm}$.

Furthermore, the goodness of the sample difference subtraction is sensitive to sample preparation. For example, in (d), the labeled sample had the same nominal lipid composition as the unlabeled sample but the lipid mixtures had been made in separate batches. In (c), the two samples were made from the same lipid batch and better subtraction was obtained than in (d). Thus, in order to obtain optimal subtraction, an unlabeled sample should be made and its spectrum taken at the same time as the labeled spectrum. These extra steps require additional time and expense.

Finally, there is an additional complication when the probe has a significant ${ }^{13} \mathrm{C}$ background and there are different amounts of labeled and unlabeled sample. Under these conditions, it is not possible to find a single scaling factor which accurately subtracts both the sample and probe natural abundance background signals.

In contrast to the many complications of sample difference spectroscopy, REDOR difference spectroscopy is quite straightforward. No judgement was needed to obtain the spectra displayed in (g) and (h) and there is complete filtering of natural abundance signals in a single sample. By obtaining $S_{0}$ and $S_{1}$ data on alternate scans, optimal compensation is obtained for spectrometer and probe drifts. This compensation scheme is not possible with sample difference spectroscopy.

Because of incomplete dephasing and/or incomplete ${ }^{1} \mathrm{H}$ decoupling, REDOR difference spectroscopy has somewhat less sensitivity than sample difference spectroscopy. For example, with the $65 \mathrm{kHz}$ TPPM decoupling used in experiments on a $6 \mathrm{~mm}$ probe, there is $10 \%$ signal loss during a $1 \mathrm{~ms}$ REDOR dephasing period.

The REDOR experiments do require synthesis of a peptide or protein with a ${ }^{13} \mathrm{C}-{ }^{15} \mathrm{~N}$-labeled pair. This is straightforward with chemical synthesis of peptides and small proteins. For example, observation of carbonyl carbons requires carboxylic ${ }^{13} \mathrm{C}$ amino acids and ${ }^{15} \mathrm{~N}$ amino acids, which are the most widely available and least expensive labeled amino acids.
In addition, for chemically synthesized peptides and proteins, the REDOR difference spectrum is dominated by signals from the labeled ${ }^{13} \mathrm{C}-{ }^{15} \mathrm{~N}$ pairs and has a very small contribution from natural abundance ${ }^{13} \mathrm{C}-{ }^{15} \mathrm{~N}$ pairs. For example, in a sample made with a 100-residue protein and a single ${ }^{13} \mathrm{C}-{ }^{15} \mathrm{~N}$ pair, the labeled:natural abundance pair ratio is $\sim 250: 1$.

\subsection{Comparison with other filtering methods}

There are recoupling methods other than REDOR which will also be a heteronuclear filter on these labeled samples. To compare methods, one key parameter is the filtering efficiency $E$, which we define as:

$E=S_{\mathrm{f}} / S_{\mathrm{CP}}$,

where $S_{\mathrm{f}}$ is the labeled signal intensity obtained with filtering and $S_{\mathrm{CP}}$ is the labeled signal intensity obtained with cross-polarization under the same conditions (e.g., MAS spinning frequency, signal averaging time, etc.) [16]. Comparison of filtering efficiencies between different methods is equivalent to comparison of signal-tonoise ratios. Because REDOR filtering is a difference method, its maximum theoretical $E$ is $\sim 0.50$. In practice, our experimental $E$ are between 0.40 and 0.45 because of imperfect echos and incomplete ${ }^{1} \mathrm{H}$ decoupling.

Heteronuclear recoupling could also be done using simultaneous frequency and amplitude modulation (SFAM), which appears to be more robust than REDOR with respect to RF inhomogeneity and resonance offsets $[43,44]$. Transferred-echo double-resonance (TEDOR) is another filtering method which has been applied to amino acids, peptides, and proteins with directly bonded ${ }^{13} \mathrm{C}-{ }^{15} \mathrm{~N}$ pairs $[45,46]$. Reported TEDOR efficiencies are between 0.05 and 0.35 [46-51]. Finally, filtering with ${ }^{15} \mathrm{~N}-{ }^{13} \mathrm{C}$ cross-polarization between directly bonded pairs has been used for amino acids, peptides, and proteins and the reported efficiencies are between 0.40 and 0.70 [50-56]. When ${ }^{15} \mathrm{~N}-{ }^{13} \mathrm{C}$ cross-polarization was applied to observe all directly bonded pairs in a crystalline $\mathrm{U}-{ }^{13} \mathrm{C},{ }^{15} \mathrm{~N}$-labeled tripeptide, $E \sim 0.40$, which is similar to what we obtained with REDOR for HFP-KKK-UF8L9G10 [51]. Some distinct positive aspects of REDOR are: (1) it is a robust method with an easy and rapid setup and (2) its duty cycle is significantly lower than other methods.

\subsection{Applications to membrane-bound fusion peptides}

Figs. 2 and 3 show application of the REDOR filter to fusion peptide samples and the kinds of information which can be obtained from the resulting spectra. In Fig. 2, the signal from the influenza fusion peptide Leu2 carbonyl is detected in different detergent and lipid environments and at different peptide:lipid ratios. The somewhat subtle changes in Figs. $2 \mathrm{~b}$ and c spectra are 
convincingly observed with the REDOR approach but would likely have been detected with less certainty using sample difference spectroscopy. The observed changes in the chemical shift as a function of environment and peptide:lipid ratio are diagnostic of the variation in the local structure (helical vs. non-helical) at this residue. The information will be used to design labeling schemes and solid state NMR experiments which further probe the membrane-bound peptide structure. The data show that the REDOR filtering/ solid state NMR approach is efficient in providing residue-specific data and is complementary to methods such as circular dichroism and infrared which provide information about the overall structure of the membrane-bound peptide. For example, our residue-specific results are consistent with infrared work on this membrane-bound peptide which suggest an equilibrium between overall helical and non-helical structure [34]. In Fig. 2a, a signal-to-noise ratio of $\sim 5$ was obtained in $\sim 24 \mathrm{~h}$ on $0.25 \mu \mathrm{mol}$ of labeled peptide at 1:120 peptide:detergent mol ratio. These data suggest that one should be able to probe peptide:lipid ratios as low as $1: 200$, which may be more biologically relevant than higher ratios. At higher fields, even lower peptide:lipid ratios should be possible.

Fig. 2a also provides an interesting cross-correlation of the solid state NMR measurements in frozen DPC detergent with structures determined in DPC micelles by solution NMR methods [30-32]. The solid state and solution NMR samples were made at about the same peptide:detergent mol ratio, so the agreement between the helical Leu-2 solid state NMR chemical shift and the helical structure observed at this residue by solution NMR methods provides cross-validation of the two methods.

In Fig. 3, REDOR filtering is applied to a membranebound fusion HIV-1 fusion peptide which was $\mathrm{U}^{13} \mathrm{C}$, ${ }^{15} \mathrm{~N}$-labeled over three residues. In this case, the approach allowed us to facilely observe the labeled backbone ${ }^{13} \mathrm{C}$, measure linewidths, and assess the potential for doing a full assignment. Although the linewidths are a few times larger than those observed in $\mathrm{U}_{-}{ }^{13} \mathrm{C},{ }^{15} \mathrm{~N}$ crystalline peptides and proteins, the recent successes in assignment of these crystalline systems suggest that a fairly long sequence in our peptide can be assigned, followed by a full structure determination $[5,39$, 51,57-59].

The HFP-KKK-UF8L9G10 peptide was also studied in frozen detergent and there were large chemical shift differences between the detergent-bound and membrane-bound peptide (data not shown). All of the differences were consistent with a change from helical to non-helical structure, analogous to what was observed for the influenza fusion peptide in Figs. 2a and c and consistent with HIV-1 fusion peptide structure in micelles $[60,61]$.

\subsection{Future applications}

It should also be possible to observe specific $\mathrm{C}_{\alpha}$ carbons by REDOR subtraction; however, only a few doubly labeled ${ }^{15} \mathrm{~N}-{ }^{13} \mathrm{C}_{\alpha}$ amino acids are commercially available. An alternate (and expensive) labeling scheme would incorporate a single uniformly ${ }^{13} \mathrm{C} /{ }^{15} \mathrm{~N}$-labeled amino acid. Less expensive labeling could be done with ${ }^{13} \mathrm{C}_{\alpha}$ on one residue and ${ }^{15} \mathrm{~N}$ on the subsequent residue. In this scheme, the ${ }^{13} \mathrm{C}_{\alpha}-{ }^{15} \mathrm{~N}$ distance is $\sim 2.5 \AA$ and the corresponding dipolar coupling is five times less than the coupling of the directly bonded pair. Hence, proportionally longer dephasing times will be required in the REDOR experiment. The filtering will still be successful but there will be lower sensitivity than that achieved with directly bonded pairs because of signal losses during the dephasing period due to incomplete ${ }^{13} \mathrm{C}-{ }^{1} \mathrm{H}$ decoupling.

Use of REDOR filtering for larger proteins will require incorporation of specific ${ }^{13} \mathrm{C}$ and ${ }^{15} \mathrm{~N}$ labels in an expression protocol $[2,41,62-64]$. A single carbonyl site can be probed using the carboxylic ${ }^{13} \mathrm{C}$-labeled amino acid of the residue of interest and the ${ }^{15} \mathrm{~N}$-labeled amino acid of the next residue in the sequence. This labeling protocol requires that the sequential pair is unique, which is less likely for larger proteins. In addition, for certain amino acids, there can be biosynthetic conversion to other amino acid types. This will only be a serious problem if the unwanted labeled amino acid happens to be next to another labeled residue in the sequence and forms an unwanted directly bonded ${ }^{13} \mathrm{C}-$ ${ }^{15} \mathrm{~N}$ pair.

We describe a specific example of biosynthetic labeling for REDOR filtering. This project (currently underway in our laboratory) investigates a 127-residue influenza fusion protein construct with sequence: GLFGAIAGFIENGWEGMIDGWYGFRHQNSEGT GQAADLKSTQAAIDQINGKLNRVIEKTNEKFHQ IEKEFSEVEGRIQDLEKYVEDTKIDLWSYNAELL VALENQHTIDLTDSEMNKLFEKTRRQLR [33]. In the first twenty-residue fusion peptide domain of this construct, 10 of the 19 sequential residue pairs are unique while the other 9 pairs are found at multiple locations in the sequence. As one example, the unique I6A7 pair can be probed with addition of $1-{ }^{13} \mathrm{C}$-Ile and ${ }^{15} \mathrm{~N}$ Ala amino acids to the expression broth. The carbonyl region of the REDOR difference spectrum will primarily contain signals from the I6A7 pair and from pairs containing a natural abundance carbonyl with directly bonded labeled ${ }^{15} \mathrm{~N}$-Ala or a labeled carbonyl ${ }^{13} \mathrm{C}$-Ile with directly bonded natural abundance ${ }^{15} \mathrm{~N}$-Ala. Assuming that each label is incorporated with $80 \%$ enrichment, the ratio of integrated intensities of the unique I6A7 pair to the other pairs is $\sim 7: 1$. Similar calculations done for other unique pairs also give approximately this ratio. Because the unique pair resonates in a narrow 
range of shifts, it will dominate the intensity spectrum to an extent greater than that implied by the 7:1 integrated intensity ratio. The other pairs which contain a natural abundance ${ }^{13} \mathrm{C}$ or ${ }^{15} \mathrm{~N}$ will resonate over a broader range of shifts because they contain multiple amino acid types found in a variety of local structures. Finally, unlike the spectra displayed in Figs. 1e-h, the REDOR difference spectra of the expressed protein samples will also contain significant aliphatic signal because of the presence of ${ }^{15} \mathrm{~N}$-labeled residues which also contain natural abundance ${ }^{13} \mathrm{C}_{\alpha}$.

\section{Conclusions}

For MAS observation of labeled backbone carbons in membrane-bound peptides and proteins, the advantages of REDOR subtraction over sample difference subtraction are shown to be: (1) superior filtering of natural abundance signals; (2) requirement of one rather than two samples; (3) better compensation for spectrometer and probe drifts; and (4) no scaling or chemical shift adjustments. The REDOR approach should be generally applicable to both chemically and bacterially synthesized peptides and proteins. In our experiments, the method provides evidence for the structural plasticity of the membrane-bound influenza fusion peptide and the feasibility of assignment on $\mathrm{U}^{13} \mathrm{C},{ }^{15} \mathrm{~N}$-labeled HIV-1 fusion peptide.

\section{Experimental}

\subsection{Samples}

HFP peptides corresponding to the $23 \mathrm{~N}$-terminal residues (sequence AVGIGALFLGFLGAAGSTMGARS) of the LAV ${ }_{\text {1a }}$ strain of the HIV-1 gp41 envelope protein were synthesized as their $\mathrm{C}$-terminal amides using a peptide synthesizer (ABI 431A, Foster City, CA) equipped for FMOC chemistry. HFP was either unlabeled, singly ${ }^{13} \mathrm{C}$ carbonyl labeled at Phe-8 (HFP-F8C), singly ${ }^{13} \mathrm{C}$ carbonyl labeled at Val-2 (HFP-V2C), or ${ }^{13} \mathrm{C}$ carbonyl labeled at Phe- 8 and amide ${ }^{15} \mathrm{~N}$-labeled at Leu9 (HFP-F8CL9N). HFP-KKK-UF8L9G10 (sequence AVGIGALFLGFLGAAGSTMGARSKKK) was synthesized with uniformly ${ }^{13} \mathrm{C},{ }^{15} \mathrm{~N}$-labeled amino acids at Phe-8, Leu-9, and Gly-10. Because of the three C-terminal lysines, HFP-KKK dissolved more quickly in aqueous solution than HFP [65].

IFP-KKK-L2CF3N peptide (sequence GLFGAIAG FIENGWEGMIDGKKK) and the IFP-GKKKL2CF3N peptide (sequence GLFGAIAGFIENGWEG MIDGGKKK) were synthesized in a manner similar to that of HFP. The IFP-KKK peptide corresponds to the $20 \mathrm{~N}$-terminal residues of the Influenza A hemagglutinin fusion protein plus three $\mathrm{C}$-terminal lysine residues to improve aqueous solubility [65]. There is also a glycine linker in IFP-GKKK. The peptides were ${ }^{13} \mathrm{C}$ carbonyl labeled at Leu-2 and ${ }^{15} \mathrm{~N}$ amide labeled at Phe-3.

Samples were prepared as previously described [19]. The HFP samples contained lipid/cholesterol mixtures reflecting the approximate lipid and cholesterol content of the HIV-1 virus and its target T cells [28]. Two mixtures of similar composition were used. "LM-2" had 1palmitoyl-2-oleoyl-sn-glycero-3-phosphocholine (POPC), 1-palmitoyl-2-oleoyl-sn-glycero-3-phosphoethanolamine (POPE), dimyristoyl-sn-glycero-3-[phospho-L-serine] (DMPS), sphingomyelin, and cholesterol in a 10:6:4:2:10 mol ratio. "LM-3" had POPC, POPE, 1-palmitoyl-2oleoyl-sn-glycero-3-[phospho-L-serine] (POPS), sphingomyelin, phosphatidylinositol (PI), and cholesterol in a 10:5:2:2:1:10 mol ratio. LM-2 was used for sample difference spectroscopy and LM-3 was used for REDOR difference spectroscopy. Samples were prepared in $5 \mathrm{mM}$ Hepes buffer ( $\mathrm{pH} 7.0$ ) and contained $\sim 0.5 \mu \mathrm{mol}$ peptide. The LM-3 was extruded into $100 \mathrm{~nm}$ diameter unilamellar vesicles prior to addition of peptide. For the LM2 samples, the total initial volume of peptide and lipid was $4 \mathrm{~mL}$ and for the LM-3 samples, the initial volume was $36 \mathrm{~mL}$. The peptide and lipid mixtures were kept at room temperature overnight and then ultracentrifuged at $130,000 \mathrm{~g}$ for $4 \mathrm{~h}$ to pellet the peptide-lipid complex. Nearly all peptide binds to lipid under these conditions and unbound peptide does not pellet. The peptide/lipid pellet formed after ultracentrifugation was transferred by spatula to a MAS rotor.

The IFP-KKK samples were prepared in a manner similar to that of the HFP/LM-3 samples. Two different detergent or lipid compositions were used: (1) dodecylphosphocholine (DPC) detergent and (2) POPC: 1-palmitoyl-2-oleoyl-sn-glycero-3-[phospho-rac-(1-glycerol)] (POPG):cholesterol in a 8:2:5 mol ratio. The compositions are similar to those used by other investigators for this peptide, except for the presence of cholesterol in our studies and its absence in their studies [30-33]. Our samples were made in $10 \mathrm{mM}$ acetate buffer $(\mathrm{pH} 5.0)$ and contained $0.25-0.7 \mu \mathrm{mol}$ peptide. The DPC sample was prepared with $200 \mathrm{mM}$ detergent and transferred directly to the MAS rotor without ultracentrifugation.

\subsection{NMR spectroscopy}

Strong ${ }^{13} \mathrm{C}$ NMR signals could not be observed above $-20^{\circ} \mathrm{C}$, presumably because of signal attenuation due to slow motion. Hence, measurements were made at -50 to $-80^{\circ} \mathrm{C}$. Chemical shifts were referenced to the methylene carbon resonance of adamantane (38.2 ppm).

Sample difference spectroscopy was done on a $9.4 \mathrm{~T}$ spectrometer (Varian VXR) using a double-resonance MAS probe equipped with a $7 \mathrm{~mm}$ diameter rotor ( $220 \mu \mathrm{L}$ sample volume). The NMR detection channel 
was tuned to ${ }^{13} \mathrm{C}$ at $100.6 \mathrm{MHz}$ and the decoupling channel was tuned to ${ }^{1} \mathrm{H}$ at $400.0 \mathrm{MHz}$. Experiments were carried out using a MAS frequency of $3500 \pm 1 \mathrm{~Hz}$. Considering the spinning limitations of the probe, this was the maximum frequency which also minimized overlap between carbonyl and other resonances. Application of $900 \mu \mathrm{s}$ of cross-polarization $(\mathrm{CP})$ at $47 \mathrm{kHz}$ was followed by signal detection with decoupling at $75 \mathrm{kHz}$. The recycle delay was $0.5 \mathrm{~s}$.

REDOR spectroscopy [1] was done on a $9.4 \mathrm{~T}$ spectrometer (Varian Infinity Plus) using triple resonance MAS probes equipped with either a $4 \mathrm{~mm}$ or a $6 \mathrm{~mm}$ diameter rotor ( 70 or $240 \mu \mathrm{L}$ sample volume). The NMR detection channel was tuned to ${ }^{13} \mathrm{C}$ at $100.8 \mathrm{MHz}$, the decoupling channel was tuned to ${ }^{1} \mathrm{H}$ at $400.8 \mathrm{MHz}$, and the third channel was tuned to ${ }^{15} \mathrm{~N}$ at $40.6 \mathrm{MHz}$. Experiments were carried out using MAS frequencies between 5000 and $8000 \mathrm{~Hz}$ and the spinning frequency was stabilized to $\pm 2 \mathrm{~Hz}$. Between 1 and $2 \mathrm{~ms}$ of crosspolarization at $50 \mathrm{kHz}$ was followed by a REDOR dephasing period and then direct ${ }^{13} \mathrm{C}$ detection. A single $50 \mathrm{kHz}{ }^{13} \mathrm{C}$ refocusing $\pi$ pulse was placed at the center of the dephasing time and ${ }^{1} \mathrm{H}$ TPPM decoupling between 65 and $95 \mathrm{kHz}$ was applied during both dephasing and detection [66]. For peptides labeled with a single ${ }^{13} \mathrm{C}-$ ${ }^{15} \mathrm{~N}$ pair, the ${ }^{13} \mathrm{C}$ transmitter was set between 155 and $170 \mathrm{ppm}$ and for the $\mathrm{U}-{ }^{13} \mathrm{C},{ }^{15} \mathrm{~N}$-labeled peptide, the ${ }^{13} \mathrm{C}$ transmitter was set to $76.9 \mathrm{ppm}$. For the $S_{1}$ acquisition, the dephasing time contained a $40 \mathrm{kHz}{ }^{15} \mathrm{~N} \pi$ pulse at the middle and end of each rotor period, while the $S_{0}$ acquisition did not contain these pulses. XY-8 phase cycling was used for the ${ }^{15} \mathrm{~N}$ pulses $[67,68]$ and the ${ }^{15} \mathrm{~N}$ frequency was near the isotropic peptide amide resonance. During the dephasing period, pulses were not actively synchronized to the rotor phase. To obtain optimal compensation of $B_{0}, B_{1}$, and spinning frequency drifts, $S_{0}$ and $S_{1}$ FID's were acquired alternately. The recycle delay was between 1 and $2 \mathrm{~s}$.

\section{Acknowledgments}

D.P.W. acknowledges a Camille and Henry Dreyfus Foundation New Faculty Award, NSF 9977650, and NIH AI47153. We thank Charles Gabrys for useful comments on the manuscript.

\section{References}

[1] T. Gullion, J. Schaefer, Rotational-echo double-resonance NMR, J. Magn. Reson. 81 (1989) 196-200.

[2] A.W. Hing, N. Tjandra, P.F. Cottam, J. Schaefer, C. Ho, An investigation of the ligand-binding site of the glutamine-binding protein of Escherichia coli using rotational-echo double-resonance NMR, Biochemistry 33 (1994) 8651-8661.

[3] T. Gullion, Introduction to rotational-echo, double-resonance NMR, Concepts Magn. Reson. 10 (1998) 277-289.
[4] D.A. Middleton, Z. Ahmed, C. Glaubitz, A. Watts, REDOR NMR on a hydrophobic peptide in oriented membranes, J. Magn. Reson. 147 (2000) 366-370.

[5] C.P. Jaroniec, B.A. Tounge, J. Herzfeld, R.G. Griffin, Frequency selective heteronuclear dipolar recoupling in rotating solids: accurate C-13-N-15 distance measurements in uniformly C-13, N-15-labeled peptides, J. Am. Chem. Soc. 123 (2001) 3507-3519.

[6] O.J. Murphy III, F.A. Kovacs, E.L. Sicard, L.K. Thompson, Sitedirected solid-state NMR measurement of a ligand-induced conformational change in the serine bacterial chemoreceptor, Biochemistry 40 (2001) 1358-1366.

[7] T.M. Forrest, G.E. Wilson, Y. Pan, J. Schaefer, Characterization of cross-linking of cell-walls of Bacillus subtilis by a combination of magic-angle spinning NMR and gas-chromatography massspectrometry of both intact and hydrolyzed C-13-labeled and N15-labeled cell-wall peptidoglycan, J. Biol. Chem. 266 (1991) 24485-24491.

[8] M.E. Merritt, A.M. Christensen, K.J. Kramer, T.L. Hopkins, J. Schaefer, Detection of intercatechol cross-links in insect cuticle by solid-state carbon-13 and nitrogen-15 NMR, J. Am. Chem. Soc. 118 (1996) 11278-11282.

[9] M. Hong, R.G. Griffin, Resonance assignments for solid peptides by dipolar-mediated C-13/N-15 correlation solid-state NMR, J. Am. Chem. Soc. 120 (1998) 7113-7114.

[10] S. Spera, A. Bax, Empirical correlation between protein backbone conformation and $\mathrm{C}-\alpha$ and $\mathrm{C}-\beta \mathrm{C}-13$ nuclear-magnetic-resonance chemical-shifts, J. Am. Chem. Soc. 113 (1991) 5490-5492.

[11] D.S. Wishart, B.D. Sykes, F.M. Richards, Relationship between nuclear magnetic resonance chemical shift and protein secondary structure, J. Mol. Biol. 222 (1991) 311-333.

[12] D.M. Gregory, M.A. Mehta, J.C. Shiels, G.P. Drobny, Determination of local structure in solid nucleic acids using double quantum nuclear magnetic resonance spectroscopy, J. Chem. Phys. 107 (1997) 28-42.

[13] J. Heller, D.D. Laws, M. Tomaselli, D.S. King, D.E. Wemmer, A. Pines, R.H. Havlin, E. Oldfield, Determination of dihedral angles in peptides through experimental and theoretical studies of $\alpha$ carbon chemical shielding tensors, J. Am. Chem. Soc. 119 (1997) 7827-7831.

[14] I. Ando, T. Kameda, N. Asakawa, S. Kuroki, H. Kurosu, Structure of peptides and polypeptides in the solid state as elucidated by NMR chemical shift, J. Mol. Struct. 441 (1998) 213 230.

[15] R.G. Griffin, Dipolar recoupling in MAS spectra of biological solids, Nat. Struct. Biol. 5 (Suppl.) (1998) 508-512.

[16] A.E. Bennett, D.P. Weliky, R. Tycko, Quantitative conformational measurements in solid state NMR by constant-time homonuclear dipolar recoupling, J. Am. Chem. Soc. 120 (1998) 4897-4898.

[17] Z. Gu, D.G. Drueckhammer, L. Kurz, K. Liu, D.P. Martin, A. McDermott, Solid state NMR studies of hydrogen bonding in a citrate synthase inhibitor complex, Biochemistry 38 (1999) 8022 8031.

[18] D.P. Weliky, A.E. Bennett, A. Zvi, J. Anglister, P.J. Steinbach, R. Tycko, Solid-state NMR evidence for an antibody-dependent conformation of the V3 loop of HIV-1 gp120, Nat. Struct. Biol. 6 (1999) 141-145.

[19] J. Yang, C.M. Gabrys, D.P. Weliky, Solid-state nuclear magnetic resonance evidence for an extended $\beta$ strand conformation of the membrane-bound HIV-1 fusion peptide, Biochemistry 40 (2001) 8126-8137.

[20] M. Hong, R.A. McMillan, V.P. Conticello, Measurement of conformational constraints in an elastin-mimetic protein by residue-pair selected solid-state NMR, J. Biomol. NMR 22 (2002) 175-179.

[21] R. Tycko, G. Dabbagh, Double-quantum filtering in magic-anglespinning NMR-spectroscopy - an approach to spectral simplifica- 
tion and molecular-structure determination, J. Am. Chem. Soc. 113 (1991) 9444-9448.

[22] A.E. Bennett, J.H. Ok, R.G. Griffin, S. Vega, Chemical-shift correlation spectroscopy in rotating solids-radio frequencydriven dipolar recoupling and longitudinal exchange, J. Chem. Phys. 96 (1992) 8624-8627.

[23] Y.K. Lee, N.D. Kurur, M. Helmle, O.G. Johannessen, N.C. Nielsen, M.H. Levitt, Efficient dipolar recoupling in the NMR of rotating solids - a sevenfold symmetrical radiofrequency pulse sequence, Chem. Phys. Lett. 242 (1995) 304-309.

[24] D.M. Gregory, G.M. Wolfe, T.P. Jarvie, J.C. Sheils, G.P. Drobny, Double-quantum filtering in magic-angle-spinning NMR spectroscopy applied to DNA oligomers, Mol. Phys. 89 (1996) 1835-1849.

[25] S.R. Durell, I. Martin, J.M. Ruysschaert, Y. Shai, R. Blumenthal, What studies of fusion peptides tell us about viral envelope glycoprotein-mediated membrane fusion (review), Mol. Membr. Biol. 14 (1997) 97-112.

[26] C. Curtain, F. Separovic, K. Nielsen, D. Craik, Y. Zhong, A. Kirkpatrick, The interactions of the N-terminal fusogenic peptide of HIV-1 gp41 with neutral phospholipids, Eur. Biophys. J. 28 (1999) 427-436.

[27] J. Yang, P.D. Parkanzky, B.A. Khunte, C.G. Canlas, R. Yang, C.M. Gabrys, D.P. Weliky, Solid state NMR measurements of conformation and conformational distributions in the membranebound HIV-1 fusion peptide, J. Mol. Graph. Model. 19 (2001) 129-135.

[28] R.C. Aloia, H. Tian, F.C. Jensen, Lipid composition and fluidity of the human immunodeficiency virus envelope and host cell plasma membranes, Proc. Natl. Acad. Sci. USA 90 (1993) 51815185 .

[29] M. Bak, J.T. Rasmussen, N.C. Nielsen, SIMPSON: a general simulation program for solid-state NMR spectroscopy, J. Magn. Reson. 147 (2000) 296-330.

[30] P.V. Dubovskii, H. Li, S. Takahashi, A.S. Arseniev, K. Akasaka, Structure of an analog of fusion peptide from hemagglutinin, Protein Sci. 9 (2000) 786-798.

[31] X. Han, J.H. Bushweller, D.S. Cafiso, L.K. Tamm, Membrane structure and fusion-triggering conformational change of the fusion domain from influenza hemagglutinin, Nat. Struct. Biol. 8 (2001) 715-720.

[32] C.H. Hsu, S.H. Wu, D.K. Chang, C.P. Chen, Structural characterizations of fusion peptide analogs of influenza virus hemagglutinin-implication of the necessity of a helix-hinge-helix motif in fusion activity, J. Biol. Chem. 277 (2002) 22725-22733.

[33] J.C. Macosko, C.H. Kim, Y.K. Shin, The membrane topology of the fusion peptide region of influenza hemagglutinin determined by spin-labeling EPR, J. Mol. Biol. 267 (1997) 11391148.

[34] X. Han, L.K. Tamm, pH-dependent self-association of influenza hemagglutinin fusion peptides in lipid bilayers, J. Mol. Biol. 304 (2000) 953-965.

[35] A.M. Christensen, J. Schaefer, K.J. Kramer, Comparison of rotational-echo double-resonance and double-cross-polarization NMR for detection of weak heteronuclear dipolar coupling in solids, Magn. Reson. Chem. 29 (1991) 418-421.

[36] J. Schaefer, REDOR-determined distances from heterospins to clusters of C-13 labels, J. Magn. Reson. 137 (1999) 272-275.

[37] C.P. Jaroniec, B.A. Tounge, C.M. Rienstra, J. Herzfeld, R.G. Griffin, Measurement of C-13-N-15 distances in uniformly C-13 labeled biomolecules: J-decoupled REDOR, J. Am. Chem. Soc. 121 (1999) 10237-10238.

[38] J.N.S. Evans, Biomolecular NMR Spectroscopy, Oxford, New York, 1995.

[39] A. Detken, E.H. Hardy, M. Ernst, M. Kainosho, T. Kawakami, S. Aimoto, B.H. Meier, Methods for sequential resonance assignment in solid, uniformly C-13, N-15 labelled peptides: quantifi- cation and application to antamanide, J. Biomol. NMR 20 (2001) 203-221.

[40] S.O. Smith, C.S. Smith, B.J. Bormann, Strong hydrogen bonding interactions involving a buried glutamic acid in the transmembrane sequence of the neu/erbB-2 receptor, Nat. Struct. Biol. 3 (1996) 252-258.

[41] J. Wang, Y.S. Balazs, L.K. Thompson, Solid-state REDOR NMR distance measurements at the ligand site of a bacterial chemotaxis membrane receptor, Biochemistry 36 (1997) 1699-1703.

[42] D.J. Hirsh, J. Hammer, W.L. Maloy, J. Blazyk, J. Schaefer, Secondary structure and location of a magainin analogue in synthetic phospholipid bilayers, Biochemistry 35 (1996) 12733-12741.

[43] R.Q. Fu, S.A. Smith, G. Bodenhausen, Recoupling of heteronuclear dipolar interactions in solid state magic-angle spinning NMR by simultaneous frequency and amplitude modulation, Chem. Phys. Lett. 272 (1997) 361-369.

[44] K. Nishimura, R.Q. Fu, T.A. Cross, The effect of RF inhomogeneity on heteronuclear dipolar recoupling in solid state NMR: practical performance of SFAM and REDOR, J. Magn. Reson. 152 (2001) 227-233.

[45] A.W. Hing, S. Vega, J. Schaefer, Transferred-echo doubleresonance NMR, J. Magn. Reson. 96 (1992) 205-209.

[46] A.W. Hing, S. Vega, J. Schaefer, Measurement of heteronuclear dipolar coupling by transferred-echo double-resonance NMR, J. Magn. Reson. Ser. A 103 (1993) 151-162.

[47] S.M. Holl, G.R. Marshall, D.D. Beusen, K. Kociolek, A.S. Redlinski, M.T. Leplawy, R.A. McKay, S. Vega, J. Schaefer, Determination of an $8-\AA$ interatomic distance in a helical peptide by solid-state NMR-spectroscopy, J. Am. Chem. Soc. 114 (1992) $4830-4833$.

[48] E.R.H. Vaneck, W.S. Veeman, Spin-density description of rotational-echo double-resonance, transferred-echo double-resonance and 2-dimensional transferred-echo double-resonance solid-state nuclear-magnetic-resonance, Solid State Nucl. Magn. Reson. 2 (1993) 307-315.

[49] S. Macholl, I. Sack, H.H. Limbach, J. Pauli, M. Kelly, C. Buntkowsky, Solid-state NMR study of the SH3 domain of $\alpha$ spectrin: application of C-13-N-15 TEDOR and REDOR, Magn. Reson. Chem. 38 (2000) 596-603.

[50] F.G. Vogt, S.M. Mattingly, J.M. Gibson, K.T. Mueller, Measurement of internuclear distances in solid-state NMR by a background-filtered REDOR experiment, J. Magn. Reson. 147 (2000) 26-35.

[51] C.M. Rienstra, M. Hohwy, M. Hong, R.G. Griffin, 2D and 3D N15-C-13-C-13 NMR chemical shift correlation spectroscopy of solids: assignment of MAS spectra of peptides, J. Am. Chem. Soc. 122 (2000) 10979-10990.

[52] J. Schaefer, R.A. McKay, E.O. Stejskal, Double-cross-polarization NMR of solids, J. Magn. Reson. 34 (1979) 443-447.

[53] M. Baldus, D.G. Geurts, S. Hediger, B.H. Meier, Efficient N-15C-13 polarization transfer by adiabatic-passage Hartmann-Hahn cross polarization, J. Magn. Reson. Ser. A 118 (1996) 140-144.

[54] B.Q. Sun, C.M. Rienstra, P.R. Costa, J.R. Williamson, R.G. Griffin, 3D N-15-C-13-C-13 chemical shift correlation spectroscopy in rotating solids, J. Am. Chem. Soc. 119 (1997) 85408546.

[55] M. Baldus, A.T. Petkova, J. Herzfeld, R.G. Griffin, Cross polarization in the tilted frame: assignment and spectral simplification in heteronuclear spin systems, Mol. Phys. 95 (1998) 1197-1207.

[56] Alia, J. Matysik, C. Soede-Huijbregts, M. Baldus, J. Raap, J. Lugtenburg, P. Gast, H.J. van Gorkom, A.J. Hoff, H.J.M. de Groot, Ultrahigh field MAS NMR dipolar correlation spectroscopy of the histidine residues in light-harvesting complex II from photosynthetic bacteria reveals partial internal charge transfer in the B850/His complex, J. Am. Chem. Soc. 123 (2001) 4803-4809.

[57] S.K. Straus, T. Bremi, R.R. Ernst, Side-chain conformation and dynamics in a solid peptide: CP-MAS NMR study of valine 
rotamers and methyl-group relaxation in fully C-13-labelled antamanide, J. Biomol. NMR 10 (1997) 119-128.

[58] A. McDermott, T. Polenova, A. Bockmann, K.W. Zilm, E.K. Paulsen, R.W. Martin, G.T. Montelione, Partial NMR assignments for uniformly (C-13, N-15)-enriched BPTI in the solid state, J. Biomol. NMR 16 (2000) 209-219.

[59] J. Pauli, M. Baldus, B. van Rossum, H. de Groot, H. Oschkinat, Backbone and side-chain C-13 and N-15 signal assignments of the $\alpha$-spectrin SH3 domain by magic angle spinning solid-state NMR at 17.6 tesla, Chembiochem 2 (2001) 272-281.

[60] D.K. Chang, S.F. Cheng, W.J. Chien, The amino-terminal fusion domain peptide of human immunodeficiency virus type 1 gp41 inserts into the sodium dodecyl sulfate micelle primarily as a helix with a conserved glycine at the micelle-water interface, J. Virol. 71 (1997) 6593-6602.

[61] D.K. Chang, S.F. Cheng, V.D. Trivedi, Biophysical characterization of the structure of the amino-terminal region of gp41 of HIV1. Implications on viral fusion mechanism, J. Biol. Chem. 274 (1999) 5299-5309.

[62] M. Kainosho, T. Tsuji, Assignment of the three methionyl carbonyl carbon resonances in Streptomyces subtilisin inhibitor by a carbon-13 and nitrogen- 15 double-labeling technique. A new strategy for structural studies of proteins in solution, Biochemistry 21 (1982) 6273-6279.

[63] D.C. Muchmore, L.P. McIntosh, C.B. Russell, D.E. Anderson, F.W. Dahlquist, Expression and nitrogen-15 labeling of proteins for proton and nitrogen-15 nuclear magnetic resonance, Methods Enzymol. 177 (1989) 44-73.

[64] D.M. Lemaster, Isotope labeling in solution protein assignment and structural-analysis, Prog. Nucl. Magn. Reson. Spectrosc. 26 (1994) 371-419.

[65] X. Han, L.K. Tamm, A host-guest system to study structurefunction relationships of membrane fusion peptides, Proc. Natl. Acad. Sci. USA 97 (2000) 13097-13102.

[66] A.E. Bennett, C.M. Rienstra, M. Auger, K.V. Lakshmi, R.G. Griffin, Heteronuclear decoupling in rotating solids, J. Chem. Phys. 103 (1995) 6951-6958.

[67] T. Gullion, D.B. Baker, M.S. Conradi, New, compensated CarrPurcell sequences, J. Magn. Reson. 89 (1990) 479-484.

[68] T. Gullion, J. Schaefer, Elimination of resonance offset effects in rotational-echo, double-resonance NMR, J. Magn. Reson. 92 (1991) 439-442. 